\title{
Thoughts on Some Problems in the Digitalization Construction of Museums
}

\author{
Ping Shi ${ }^{1, *}$ Yifan Feng ${ }^{1}$
}

\author{
${ }^{1}$ Xi'an University, Xi'an, Shaanxi 710065, China \\ *Corresponding author. Email: mc1126@163.com
}

\begin{abstract}
With the rapid development of computer and Internet technology, the traditional management and information storage methods of museums have been unable to meet the needs of today's society, and the digitalization construction of museums has become an irresistible trend of the times. This paper introduces the significance of museum digitalization construction, shows the advantages of museum digitization, and provides some suggestions for the ways of museum digitalization construction.
\end{abstract}

Keywords: museum, digitalization construction, effective way

\section{INTRODUCTION}

The museum is a place for collecting, displaying and researching the objects representing the natural and human cultural heritages. It is a permanent public welfare institution that provides knowledge and culture for the public. The museum is not only a place for collecting precious cultural relics and other material data, but also an important place for spreading scientific knowledge, conducting ideological and moral education and scientific research, and enriching people's cultural life.

In recent years, with the development of computer and network technology, digital technology has been applied to museum work. All museums have carried out digitalization construction. The digitization of museum resources refers to a comprehensive process, in which the museum uses various digital means to collect, store, and process related resources with collections as the core to form a complete digital content system, and with the overall information construction of the museum, it can improve the management and utilization of cultural relics, and better play the social service role of museum resources.

With the application of digital technology, visitors can have interactive immersive experience with the help of museum website, digital projection and virtual image, so as to understand the historical stories and cultural connotation of cultural relics more intuitively and deeply. With the application of websites and Apps, visitors can "visit" the museum at home. The museum is displayed in front of the visitors with a brand-new image, which attracts more and more visitors, and makes the museum really live.

\section{THE SIGNIFICANCE OF MUSEUM DIGITALIZATION CONSTRUCTION}

\section{A. Being conducive to the inheritance of culture}

As a cultural symbol of a city and even a country, museum carries rich cultural connotation. Culture is the soul of a country and a nation. As a museum, it is necessary to serve the overwhelming majority of the people as the focus and foothold of the work. It should focus on the cultural benefits of the people, make full use of the advantages of the cultural resources of the museum, excavate the value of the cultural resources of the museum, release the potential of the cultural resources of the museum, provide the people with the most simple, direct, practical, timely and effective, and most willing to accept, multi-level, diversified cultural services, and constantly meet the growing needs of the people for a better life. For a long time, due to improper protection of cultural relics, most cultural relics will be damaged as the time goes. It is urgent to take the digital protection for cultural relics. Cultural relics information will be made into electronic files, and can be permanently preserved, which is conducive to the inheritance of cultural heritage.

\section{B. Being conducive to the tour}

With the digitization construction of the museum, those who can't visit the museum for objective reasons can watch the exhibition at home through the smart client-side. At present, the common online display form is virtual reality. Virtual reality is a kind of technology that can form simulation environment and things. Visitors can carry out various activities in the virtual environment as in the real world. Its biggest feature is that it allows the visitors to completely blend into them, with good interactivity. With the visiting routes 
presented in the computer, the virtual exhibition hall allows visitors to browse the cultural relics.

If visitors are curious or interested in a collection in the virtual exhibition hall, they can click it directly, and the enlarged pictures, three-dimensional models and detailed relevant information of the collection will appear, providing a public browsing channel on the Internet for the visitors.

Shaanxi Museum (Weinan) has built up its own publicity platform by using digital technology, such as micro-blog, WeChat official account, and short video of "Tiktok,". The website uses advanced digital means such as dynamic simulation and 3D demonstration to present the rich cultural relics in the museum to the netizens. It not only meets the public's most basic knowledge query, but also provides rich experience and wonderful visual enjoyment for the public, breaking the time and space constraints, and better meeting the needs of visitors.

\section{Being conducive to academic research and exchange}

Academic research is the driving force for the development of museums. With the digitization construction, the cultural relics information will be transformed from traditional documents into digital information base by digital technology, which improves the use and management efficiency of cultural relics researchers and related staff. First of all, in the actual work, the museum uses digital multimedia means to upgrade all aspects of the physical data. The highdefinition photos, realistic 3D model and other information data are more comprehensive than the physical observation in some aspects, so that researchers can find the details that are easy to be ignored. Secondly, researchers can extract cultural relic information through search engine, shorten working time, and easily find the existing rules of cultural relics under big data, which is conducive to the development of cultural relics research.

Every museum hopes to establish a good cooperative relationship with other museums in China or the world, and carry out substantive academic exchanges. In the past, researchers published their research results or materials in Chinese or foreign journals. With the digitization construction, researchers can publish their research results on the Internet, which is convenient for other researchers and scholars who have the interests. The museums can also connect its information system with the Internet to facilitate Chinese and foreign scholars to access relevant materials through the Internet, which can not only carry out Chinese and international academic research and exchange, but also improve the international reputation of the museum.

\section{PROBLEMS IN MUSEUM DigitizATION CONSTRUCTION}

With the support of national policies and the growing spiritual needs of people, museum digitization has developed rapidly in China. However, due to the short development time, there are still various problems in the practical application of museum digitization construction, which need the attention.

\section{A. The advancement of technical equipment is not universal}

Strengthening the construction of digitization museum has become the development trend of the times, but the technology and equipment of digitization construction cannot be popularized. Digitization museums need professional technical facilities, such as computers that can store big data resources, 3D projection facilities, professional photography equipment, and relevant professional talents. However, due to the short history of digitization museum development in China, there is no solid foundation, different degree of government policy attention in different regions, and imbalance of regional economic development, leading to the lack of technical equipment and related talents in some regional museums. The digitization construction of museums should be popular nationwide, not the characteristics of some museums.

\section{B. The awareness of resource sharing is insufficient}

Museums have a depth of knowledge that textbooks cannot provide. For the Chinese people, the educational significance of museums is limited to museums. Although some information can be obtained from some websites, there are some hysteresis and limitations. And the rich data resources of museums cannot be utilized. It shows that the design of museum network platform is mainly for museum publicity, lacking the consciousness of sharing cultural relics resources. This is a great waste of museum resources, which is not in line with the development trend of digital museum.

\section{The information search is not strongly convenient}

The traditional information search of museums mainly relies on the written records and the display of physical cultural relics. First of all, for museum visitors, they can only get the exhibition information of the cultural relics on display, but cannot obtain other knowledge, which has limitations. Secondly, the composition of museum visitors is complex. Due to the limitation of body, language and age, exhibition information may not be received completely. Finally, the museum traditionally divides the exhibits into historical, artistic, scientific and comprehensive types, which makes it difficult for the visitors to combine their artistic, scientific and historical values, resulting in a certain sense of distance. Therefore, it is required to pay 
attention to these problems when creating museum information search through digital technology.

\section{EFFECTIVE WAYS TO PROMOTE DIGITIZATION CONSTRUCTION OF MUSEUMS}

After the theory of museum digitization construction has been introduced into China, there will be some problems even if there are foreign solutions for museum digitization construction and cultural relics management. To use information resources with low cost and high efficiency in huge information data and share resources, and promote the digital construction of museums, there are several ways.

\section{A. Comprehensively improving the professional equipment level of museum}

One of the main factors affecting the digitization construction of museums is the level of science and technology of museums. The museum can solve this problem by purchasing professional technical equipment and introducing professional working team. First of all, the team can produce images, audio, 3D projection, etc., restore the cultural relics, structural drawings of cultural relics components, and update the exhibition mode of museum. Secondly, with the help of technical equipment, museum can build the collection information database and museum control system to promote the digitization construction of the museum. The use of technical equipment is the material basis for the digitization museum construction. The equipment mainly includes large professional digital cameras, high-precision large format plane scanners, highprecision plane duplicators, 3D building scanners, standard-definition and high-definition digital cameras. In addition, there are equipment control software, color management equipment and software.

\section{B. Using multi technologies to customize personalized services for the visitors}

Due to the old exhibition contents, the lack of renewal of exhibits and the lack of interesting interpretation in traditional museums, some museums have cooled down. How can museums get out of the predicament and attract more visitors? The author thinks that it is necessary to make use of the wide application of digital technology. It is better to meet the special needs of the visitors through the construction of the website, the development of smartphone Apps, multimedia display and other means. Among these projects, multimedia display is an important one. It has the characteristics of large scale, many projects, new technology and serialization.

Taking the capital museum as an example, the multi-media exhibition project of the Capital Museum covers many items, such as exhibition, opening, service and visitor interaction. It was the largest multi-media program group produced by Chinese museums at that time. These multi-media exhibition projects use a variety of mature and stable new technologies, which greatly improve the overall expression effect of the exhibition, supplement the shortage of physical exhibits, make the complex and abstract knowledge vivid and intuitive, and strengthen the overall atmosphere of the exhibition. It has greatly aroused the interest of visitors and achieved the effect of teaching in entertainment.

\section{Digitization storage of cultural relics information and establishment of a complete database}

In order to make digitization storage of cultural relic information, it is required to carry out the information data collection, record the basic information such as image data, pictures, text description, 3D stereo projection and so on. Secondly, according to the unified national standards, the information of cultural relics is classified and the storage location of resources is reasonably divided. The database is stored systematically. In the face of different professional management and user retrieval, it can provide a more convenient method for the management and research through hierarchical retrieval, image retrieval, etc., and protect the cultural relics information in the collection. Finally, the database is applied in museum exhibition and network platform sharing.

\section{Conclusion}

It has been proved that the construction of digitization museum conforms to the needs of the times and is the inevitable result of social development. The digitization construction of museum collection management system, collection information database, information sharing platform and web page improves the efficiency of museum management system, the construction of information data of cultural relics and the protection of cultural relics. It also broadens the sharing platform and multi-level search of museum information resources, so that it cannot only protect cultural relics information, but also meet the various needs of museum visitors for spiritual culture. Against the background of "Internet plus", the development of digitization museum in China is the new trend and new direction for the future development of museums.

\section{References}

[1] Yao An. 12 Lectures on the Museum [M], Beijing: Science Press, 2001. (in Chinese)

[2] Quan Sha. Shaanxi Digital Museum Construction Inspiration [J], Shaanxi: New Western (Theory Edition), 2006(06). (in Chinese)

[3] Tang Yuyang. Immovable Cultural Heritage: Scientific and Dynamic Protection Concept [J], Beijing: China Cultural Heritage, 2004 (03). (in Chinese) 
[4] Wang Hongjun. Fundamentals of Chinese Museology [M], Shanghai: Shanghai Ancient Books Publishing House, 2001.12. (in Chinese)

[5] Gao Yuan. Analysis of Problems in the Construction of Digital Museum [J], Shenzhen: Shenzhen Museum, 2019. (in Chinese)

[6] Complation group. "Introduction to Museology" [M], Beijing: Higher Education Press, 2009. 1. (in Chinese)

[7] Cao Bingwu. "Museum Observation" [M], Beijing: Xueyuan Publishing House, 2005. 9. (in Chinese) 